\title{
The effect of the coronavirus disease (COVID-19) on the physical fitness of children aged 16, living in Kosovo
}

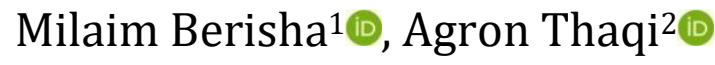 \\ ${ }^{1}$ School of Physical Education and Sport, Istanbul Gelişim University, Turkey. ${ }^{2}$ Tetovo State University, Department of Kinesiology, North \\ Macedonia.
}

\begin{abstract}
The aim of the study was to determine the effect of coronavirus disease (COVID-19) on the physical fitness of children aged 16, living in Kosovo. The research was conducted on a sample of 41 students aged 16 years \pm 6 months, who are high school students from the Republic of Kosovo ( $n=41$ boys). Physical tests included in the study to measure the anthropometric and motor abilities included, height, weight, body mass index, balance, flexibility, strength continuity, explosive force, and anaerobic peak power. The calculation of the data was made by using the SPSS 24 software program. The One-Way repeated measure ANOVA Analysis was used to calculate the statistical data of the tests that were included in the study (years: 2018, 2019, and 2020). The study results have shown statistically significant effects of the pandemic on motor abilities, such as on explosive force and anaerobic peak power. However, there is no significant effect of the pandemic on anthropometric characteristics, balance, and flexibility ( $p>0.05)$. The effects of the pandemic on the health of the children living in Kosovo were less in comparison with the effects of the pandemic reported by the World Health Organization and other countries. Moreover, the study also showed decreases in motor abilities in the years when the COVID-19 pandemic had not occurred.
\end{abstract}

Keywords. Kosovo, pandemic (COVID-19), physical fitness.

\section{Introduction}

The COVID-19 pandemic is a worldwide disease. Across the world, physical distancing has been established, limiting people's daily activities, and recommending people to stay in their homes due to the pandemic. This necessarily means that most people will spend their time indoors. Physical distance means that people will have much less opportunity to engage in physical activities, especially when it is known that activities such as regular physical education lessons at schools, sports teams training, walking in nature, cycling and other sports activities are limited.

The closure of schools, in order to prevent the spread of COVID-19, is estimated to have affected about $67 \%$ of the world's children and youth (UNESCO, 2020). The increase in physical inactivity during the COVID-19 pandemic is explained by two important reasons. The first relates to the fact that even before the pandemic, physical inactivity was apparent, and the second, to the imposition of a completely limited life, which both have significantly influenced the decline in physical fitness (Pitanga et al., 2020).

Increased physical inactivity, associated with longer periods of sedentary behavior can cause cardiovascular disease and mortality, due to a variety of reasons (Young et al., 2016). On the other hand, physically active individuals have significantly reduced mortality due to cardiovascular diseases, even if they have remained inactive for a long time because they have improved their cardio-respiratory ability that prevents various chronic diseases (Warren et al., 2010; Lavie et al., 2019).

Physical activity is closely related to the mental health and well-being of people. Physically active individuals, usually experience less stress, depression,

凶M. Berisha, e-mail: mberisha@gelisim.edu.tr

Received: May 03, 2021 - Accepted: June 27, 2021 - Published: June 30, 2021

To Cite: Berisha, M. \& Thaqi, A. (2021). The effect of the coronavirus disease (COVID-19) on the physical fitness of children aged 16, living in Kosovo. Turk J Kinesiol, 7(2), 66-72. DOI: 10.31459/turkjkin.932102 
and anxiety (Chekroud et al., 2018). Physical activity in recent years is being considered as a possible treatment against depression and anxiety, instead of pharmaceuticals (Carek et al., 2011). A particularly promising benefit of physical activity arises from research done in an outdoor environment with increased exposure to nature. Research has shown that staying in nature for a long time increases the positive results of psychological health, including happiness, mood and self-esteem increases vitality, and reduces stress (Nguyen \& Brymer, 2018). Activities such as these were restricted with COVID-19 prohibitions.

In Kosovo, the first case of COVID 19 was confirmed on March 13, 2020. From March 24, there was a total closure due to the pandemic and this closure lasted for several months. During this time, the physical distance has been necessary, and all physical activities have been interrupted. The closure of schools around the world, in order to prevent the spread of COVID-19, is estimated to have affected all children. So, the effects of the pandemic on children's health, are estimated to a large degree by international institutions, such as the WHO. However, we do not suppose that the effect of the pandemic on health in Kosovo will not be in the same ratio as it is in the other countries in the world. This is because of some advantages the children living in Kosovo pose, such as living in rural areas, having good physical status, etc. (NIPHK, 2020).

Nevertheless, the determination of the effect of the pandemic on children's health must be measured using scientific methods. Considering this, we have conducted research, whose aim is to determine the effect of the pandemic (COVID-19) on the physical fitness of children aged 16 living in Kosovo. Based on this purpose, this study aims to determine a new strategy for coping with situations that challenge the wellness status of the children living in Kosovo.

\section{Methods}

Determination of the pandemic effects on children's physical fitness made by comparing the norm values of physical fitness of the children made in 2018, 2019, and 2020. In this way, it can be determined that it has chosen a randomized longitudinal model of the study. The data obtained during 2018 were compared with the data obtained during the 2019 and 2020 years. The sample of entities has been the same in all years, the variables also have been the same and the age of the students has also been the same.
The research was conducted on a sample of 41 students aged 16 years \pm 6 months, who are students of a high school in the Republic of Kosovo ( $n=41$ boys). The participants and their parents were informed of the benefits and risks of the investigation before signing an institutionally approved informed consent document to participate in the study.

The students and their parents were informed of the benefits and risks of the investigation before signing an institutionally approved informed consent document to participate in the study. The study was approved by the Board of the Professional High School "Fehmi Lladroci" on 12 April 2021.

Selection of the tests in the study was made according to the tests' representation of the physical fitness (health) of the children. Another factor of the test selection was the fact that it needed to find tests were made (handle test scores or values to compare with the test scores which were handled after coronavirus COVID-19) before in Kosovo on the children as the study sample.

\section{Physical Fitness Tests}

Height $(\mathrm{H})$ was measured by martin anthropometry and the data was read with an accuracy of $0.1 \mathrm{~cm}$. The body weight and body mass index $\left(\mathrm{kg} / \mathrm{m}^{2}\right)$ were measured with medical scales (Tanita BC $545 \mathrm{~N}$ Innerscan Segmental Personal Body Analysis) and the data was read with an accuracy of $0.1 \mathrm{~kg}$. Countermovement jump (CMJ) is jumping up from the squat position with maximal speed. The explosive force property exhibited by its muscles depending on the maximal force was measured (Bayraktar, 2010; Mackala et al., 2013). Standing broad jump (SBJ) measurements were conducted according to the Nešić' protocol (Nešić et al., 2013). Throwing medicine ball (THMB) is a test for assessment of explosiveness of the shoulder area (the results were obtained with an accuracy of $1 \mathrm{~cm}$ ) (Nešić et al., 2013). Sit-ups (SU30s) tests were measured by bending the elbows from the straight position, then approaching the ground and straightening the elbows again. Correctly done and completed sit-ups were counted and recorded as a result (Günay et al., 2017). Push-ups (PU30s) have validity and reliability to measure the muscular strength endurance of the chest and back arm muscles (Baumgartner et al., 2002; Hashim, 2012). The seat and reach test (SRT) were used to measure flexibility and is performed on a flexibility measurement chart, with a 
length of $35 \mathrm{~cm}$, a width of $45 \mathrm{~cm}$, and a height of $32 \mathrm{~cm}$, the dimensions of the top plate, $55 \mathrm{~cm}$. length, $45 \mathrm{~cm}$, the width of the top plate is $15 \mathrm{~cm}$ (Günay et al., 2017). The flamingo balance test (FBT) is used to calculate the overall balance of the body. The ability to successfully maintain a state of equilibrium is assessed (Jürimäe \& Volbekiene, 1998; Şahan, 2017).

\section{Data Analysis}

The calculation of the data was made by using the SPSS 24 program. To analyze the general values of the test, descriptive statistics were used. The normality of the data was determined by the Kolmogorov-Smirnov test ( $p>0.05)$. Based on the fact that data resulted to be normal in comparing the data of three years $(2018$, 2019, and 2020), the one-way repeated measure ANOVA test was used.

\section{Results}

Table 1 shows that there is no significant difference between anthropometric characteristics (W, BMI) made in 2018, 2019 (December), and 2020 (December) ( $p>0.05$ ). Thus, the results of the studies showed no significant effect of the COVID-19 restrictions that started in March 2021, i.e., 12 months under COVID-19 restrictions.

Table 2 has shown that there is no significant difference between motor abilities such as FBT, SRT, and PU30s tests made in 2018, 2019 (December), and
2020 (December) ( $p>0.05)$. Thus, the results of the studies showed no significant effect of the COVID-19 restrictions which started in March 2021, i.e., 12 months under COVID-19 restrictions. However, data analysis has shown a significant difference between the results of the SU30s test made in 2018, 2019 (December), and 2020 (December) $(\mathrm{p}<0.05)$.

According to the data analysis given in Table 3, statistically significant differences were seen between the results on the SBJ, CMJ, ANPP, and ANAP tests made in 2018, 2019 (December), and 2020 (December) ( $p>0.05$ ). Similarly, in these tests, there is no significant difference between the results of the THMB test made in 2018, 2019 (December), and 2020 (December) ( $>>0.05)$.

\section{Discussion}

The study made to determine the COVID-19 effects on health and motor abilities of children living in Kosovo (Gllogoc zone) has shown that there is some negative effect that may be caused by the COVID-19 restrictions. Due to the COVID-19 pandemic, the first restrictions in Kosovo started in March 2020, where all schools were closed, and education switched to online platforms. The values of the motor abilities made in December 2020 , were compared with the norm values of the motor abilities of the children living in Kosovo, and the result of the same motor abilities which were taken to monitor the children's development in school in the 2019 year (Berisha, 2018).

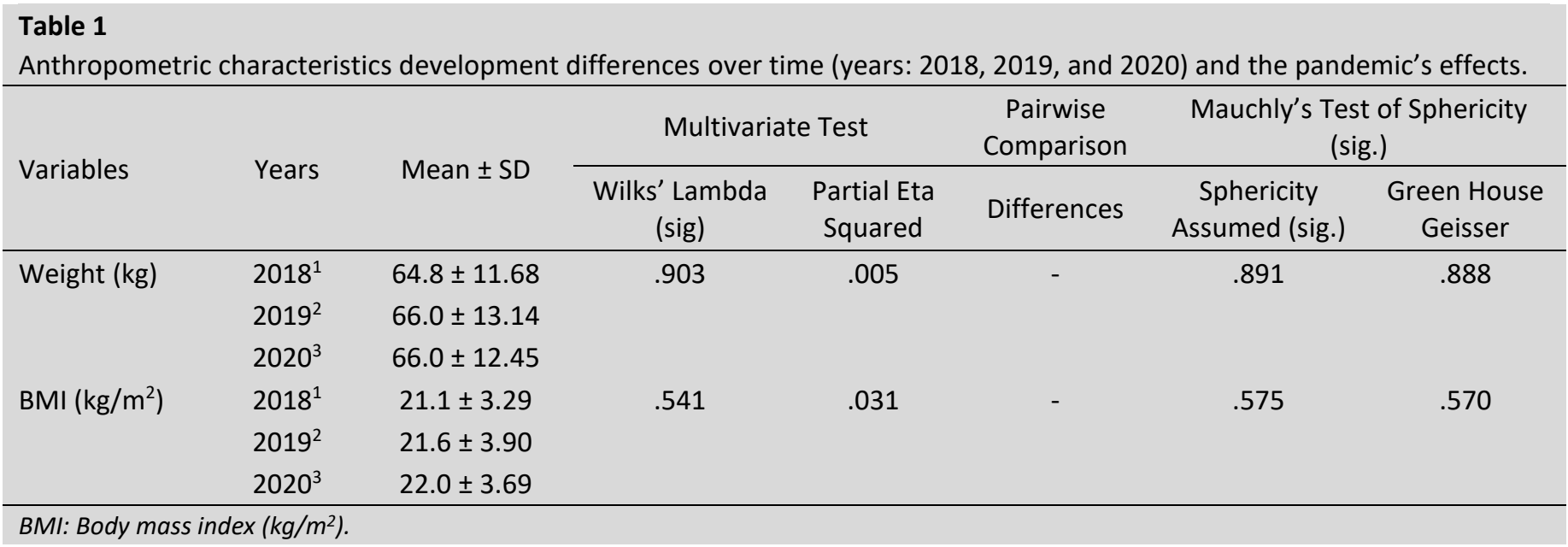


Table 2

Balance, flexibility, and strength continuity development differences over time and the pandemic's effects.

\begin{tabular}{|c|c|c|c|c|c|c|c|}
\hline \multirow{2}{*}{ Variables } & \multirow{2}{*}{ Years } & \multirow{2}{*}{ Mean \pm SD } & \multicolumn{2}{|c|}{ Multivariate Test } & \multirow{2}{*}{$\begin{array}{c}\text { Pairwise } \\
\text { comparison }\end{array}$} & \multicolumn{2}{|c|}{ Mauchly's test of sphericity (sig.) } \\
\hline & & & $\begin{array}{c}\text { Wilks' } \\
\text { Lambda (sig) }\end{array}$ & $\begin{array}{l}\text { Partial Eta } \\
\text { Squared }\end{array}$ & & $\begin{array}{c}\text { Sphericity } \\
\text { Assumed (sig.) }\end{array}$ & $\begin{array}{l}\text { Green House } \\
\text { Geisser }\end{array}$ \\
\hline \multirow{2}{*}{$\begin{array}{l}\text { FBT } \\
\text { (fall/60sec) }\end{array}$} & $2018^{1}$ & $7.32 \pm 4.56$ & .962 & .002 & - & .964 & .955 \\
\hline & $2019^{2}$ & $7.41 \pm 6.74$ & & & & & \\
\hline \multirow{2}{*}{$\mathrm{SRT}(\mathrm{cm})$} & $2019^{2}$ & $14.3 \pm 8.01$ & & & & & \\
\hline & $2020^{3}$ & $17.1 \pm 6.14$ & & & & & \\
\hline \multirow{2}{*}{$\begin{array}{l}\text { SU30s } \\
\text { (reps/30sec) }\end{array}$} & $2018^{1}$ & $26.2 \pm 4.87$ & .000 & .583 & $1>2$ & .000 & .000 \\
\hline & $2019^{2}$ & $19.7 \pm 3.29$ & & & $1>3$ & & \\
\hline $\begin{array}{l}\text { PU30s } \\
\text { (reps/30sec) }\end{array}$ & $2020^{3}$ & $21.2 \pm 7.70$ & & & & & \\
\hline
\end{tabular}

FBT: Flamingo balance test (fall/60sec); SRT: Seat and reach test (cm); SU30s: Sit-ups (reps/30sec); PU30s: Push-ups (reps/30sec).

\section{Table 3}

Anaerobic power and explosive force development differences over time and the pandemic's effects.

\begin{tabular}{|c|c|c|c|c|c|c|c|}
\hline \multirow{2}{*}{ Variables } & \multirow{2}{*}{ Years } & \multirow{2}{*}{ Mean \pm SD } & \multicolumn{2}{|c|}{ Multivariate Test } & \multirow{2}{*}{$\begin{array}{c}\begin{array}{c}\text { Pairwise } \\
\text { Comparison }\end{array} \\
\text { Differences }\end{array}$} & \multicolumn{2}{|c|}{ Mauchly's Test of Sphericity (sig.) } \\
\hline & & & $\begin{array}{c}\text { Wilks' } \\
\text { Lambda (sig) }\end{array}$ & $\begin{array}{c}\text { Partial Eta } \\
\text { Squared }\end{array}$ & & $\begin{array}{c}\text { Sphericity } \\
\text { Assumed (sig.) }\end{array}$ & $\begin{array}{c}\text { Green House } \\
\text { Geisser }\end{array}$ \\
\hline \multirow[t]{3}{*}{$\mathrm{SBJ}(\mathrm{cm})$} & $2018^{1}$ & $196.6 \pm 32.52$ & .000 & .337 & $1>2$ & .000 & .000 \\
\hline & $2019^{2}$ & $178.2 \pm 24.63$ & & & $1>3$ & & \\
\hline & $2020^{3}$ & $163.7 \pm 27.69$ & & & $2>3$ & & \\
\hline \multirow[t]{3}{*}{ THMB $(\mathrm{cm})$} & $2018^{1}$ & $492.8 \pm 109.45$ & .073 & .126 & - & 0.70 & 0.77 \\
\hline & $2019^{2}$ & $485.6 \pm 53.42$ & & & & & \\
\hline & $2020^{3}$ & $456.8 \pm 66.17$ & & & & & \\
\hline \multirow[t]{3}{*}{$\mathrm{CMJ}(\mathrm{cm})$} & $2018^{1}$ & $36.6 \pm 7.40$ & .000 & .375 & $1>2$ & .000 & .000 \\
\hline & $2019^{2}$ & $29.7 \pm 4.98$ & & & $1>3$ & & \\
\hline & $2020^{3}$ & $31.4 \pm 6.08$ & & & & & \\
\hline \multirow{3}{*}{$\begin{array}{l}\text { ANPP } \\
\text { (wat/kg) }\end{array}$} & $2018^{1}$ & $43.0 \pm 10.13$ & .002 & .268 & $1>2$ & .000 & .000 \\
\hline & $2019^{2}$ & $34.9 \pm 7.23$ & & & $1>3$ & & \\
\hline & $2020^{3}$ & $37.2 \pm 7.92$ & & & & & \\
\hline \multirow{3}{*}{$\begin{array}{l}\text { ANAP } \\
\text { (wat/kg) }\end{array}$} & $2018^{1}$ & $23.5 \pm 5.19$ & .001 & .285 & $1>2$ & .000 & .000 \\
\hline & $2019^{2}$ & $19.2 \pm 3.76$ & & & $1>3$ & & \\
\hline & $2020^{3}$ & $20.5 \pm 4.07$ & & & & & \\
\hline
\end{tabular}

SBJ: Standing broad jump (cm); THMB: Throwing medicine ball $(\mathrm{cm})$; CMJ: Countermovement jump (cm); ANPP: Anaerobic peak power (wat $/ \mathrm{kg})$; ANAP: Anaerobic average power (wat $/ \mathrm{kg})$. 
We have reason to believe that the COVID-19 restrictions negatively affected the health and children's motor abilities based on the comparison analysis applied in the results of the same tests made in 2018 and 2019. In light of this, according to the data analysis given in the study, it can be seen statistically significant decreases of motor abilities such as power (explosive force) of the children from 2019 (December) to 2020 (December). In the meeting of the members of the physical education and sports council of Europe, almost all participants reported a decrease in their children's motor abilities (WHO, 2020). Based on some performance measurements Slovenian children have lost around $25-30 \%$ of their motor abilities because of the restrictions and schools closing caused by the COVID-19 pandemic.

Besides this, China as the first country to be affected by COVID-19 and also the first to implement and lift the blockade measures provides valuable evidence and references to other countries. The study of Zhou et al. (2021), using a large sample of young Chinese, found that COVID-19 had a significant and adverse effect on young people's physical activity and sedentary posture, and such effects persisted for at least 3 months. Specifically, physical activity was significantly reduced, but sitting time was significantly increased during the blockage (Zhou et al. 2021).

The research shows that during the pandemic period, students were less physically active than they would have been during open school. In addition to the lack of a scheduled school day of physical activity, children have also stayed home instead of walking to and from school, entering and leaving classes, and playing in the schoolyard during the holidays. The vast majority of children aged 6-15 do organized sports one or more days a week, which they have not been able to because of the shutdowns. Because of these factors, it is plausible that prior to the pandemic, students would have achieved an average of one or two hours per week of physical activity or would have been able to do so before the restrictions imposed, due to COVID-19 (Astrid et al., 2021).

The significant decreases were detected in the other motor abilities such as strength continuity, and anaerobic power. However, these significant decreases in motor abilities were not detected in the data just taken before the COVID-19 pandemic and after it. Similarly, we detected significant decreases in motor abilities from 2018 to 2019, data that both were made before the COVID-19 pandemic. Therefore, decreases of the motor abilities before starting pandemic make us believe that COVID-19 did not cause negative effects as forecast.

Whether caused by COVID-19, there are decreases in motor abilities of the children just in two years, which is dramatic and needs deep examinations and standard development that can be used to monitor the children's physical fitness, in term of years of months.

In addition, the study has shown that there is no significant difference between anthropometric characteristics such as body weight and body mass index values made in 2018, 2019 (December), and 2020 (December). It may be connected to the fact that it impacts negatively or positively on body weight and body mass index may occur in a longer period of time under restrictions. Besides this, around $60 \%$ of Kosovo's children live in rural areas, they might be able to be active in nature where the restrictions were not extended even when physical education and sport lessons are not regularly being applied (KAS-Kosovo Agency of Statistics, 2019).

As a result of the study, the effects of the COVID-19 pandemic on Kosovo's children's health and motor abilities, seem to be less effective than we have seen and reported by the WHO and other countries in Europe. In light of this, we can determine some factors, which may be the reason why the COVID-19 pandemic has less effect in Kosovo compared to Europe and other countries. When analysis of more than 25 factors related to health and compared between Kosovo and Europe, Kosovar children were found to have better health conditions (Berisha, 2018). In addition, as mentioned above, the percentage of the people who live in rural and urban areas, within nature, and the population density (KAS-Kosovo Agency of Statistics, 2019), make a more favorable condition to cope with a pandemic such as a COVID-19.

\section{Conclusions}

In conclusion, the effects of the COVID-19 pandemic in Kosovo's children's health and motor abilities seem to be less effective than we have seen and reported by the WHO and other countries in Europe. Based on this, we can determine some factors that may be the reason why the COVID-19 pandemic has less effect in Kosovo compared to Europe and other countries. Based on many studies that examined more than 25 factors related to health and compared between Kosovars and 
Europeans, it was found that Kosovar children are in better health. Moreover, as mentioned above, the percentage of people who live in rural and urban areas, within nature, and population density (KAS-Kosovo Agency of Statistics, 2019), make a more favorable condition to cope with a pandemic such as a COVID-19.

Further to the study aims to determine the COVID19 pandemic effect on children's health we have determined a drastic decrease in children's motor abilities from 2018 to today. Thus, we strongly suggest conducting similar research, to determine the reasons for these decreases and create needed mechanisms to prevent them. Moreover, more than ever before, we have reason to believe that physical activities must be part of our lives, the hours of physical education applied per week and sports lesson at schools must be increased and sports institutions, such as sports science faculties, federations, and teams must be supported more in order to improve public health. Instead of staying at home, not working, not shaking hands, and spending billions on vaccines which have side effects that are unclear, the only way humans surviving versus natural disasters, such as a pandemic or other factors, is being healthy and having strong immunity.

\section{References}

Astrid, R., Marte, B.B \& Cecilie, P.D. (2021). The impact of COVID-19 and homeschooling on students' engagement with physical activity. Sports Act Living, 2, 589227. doi: 10.3389/fspor.2020.589227.

Baumgartner, T. A., Oh, S., Chung, H. \& Hales, D. (2002). Objectivity, reliability, and validity for a revised push-up test protocol. Meas Phys Educ Exerc Sci, 6(4), 225-42.

Bayraktar, I. (2010). Normative study of some physical and physiological parameters of 13-17 age group athletes and wrestlers. Doctoral Thesis, Gazi University, Institute of Health Sciences, Turkey.

Berisha, M. (2018). Determination of norm values in evaluation of physical and bio-motoric developments in 11-17 years children in Kosovo. Doctoral thesis, Sakarya University, Turkey.

Carek, P.J., Laibstain, S.E. \& Carek, S.M. (2011). Exercise for the treatment of depression and anxiety. Int J Psychiatry Med, 41, 15-28.

Chekroud, S.R., Gueorguieva, R. \& Zheutlin, A.B. (2018). Association between physical exercise and mental health in 12 million individuals in the USA between 2011 and
2015: A cross-sectional study. Lancet Psychiatry, 5, 736746.

Günay, M., Tamer, K., Cicioğlu, İ. \& Şıktar, E. (2017). Spor fiziyolojisi ve performans ölçüm testleri. $4^{\text {th }}$ Edition, Ankara: Gazi Kitabevi Tic. Ltd. Şti. [In Turkish]

Jürimäe, T. \& Volbekiene, V. (1998). Eurofit test results in Estonian and Lithuanian 11 to 17-year-old children: A comparative study. Eur J Phys Educ, 3(2), 178-184.

KAS-Kosovo Agency of Statistics. (2019). Population Assessment.

Lavie, C.J., Ozemek, C., Carbone, S., Katzmarzyk, P.T. \& Blair, S.N. (2019). Sedentary behavior, exercise, and cardiovascular health. Circ Res,124(5), 799-815.

Mackala, K., Stodółka, J., Siemienski, A. \& Coh, M. (2013). Biomechanical analysis of squat jump and countermovement jump from varying starting positions. J Strength Cond Res, $27(10), 2650-2661$.

National Institute of Public Health of Kosovo NIPHK. (2020).

Nešić, G., Ilić, D., Majstorovic, N., Grbic, V. \& Osmankac, N. (2013). Effects of training on basic and specific motor abilities of volleyball players aged 13-14 years. SportLogia, 9(2), 119-27.

Nguyen, J.\& Brymer, B. (2018). Nature-based guided imagery as an intervention for state anxiety. Front Psychol, 9, 1858.

Pitanga, F.J.G., Beck, CC. \& Pitanga, C.P.S. (2020). Physical activity and reducing sedentary behavior during the coronavirus pandemic. Arq Bras Cardiol, 114(6), 10581060.

Şahan, A. (2017). Puberte döneminde yapılan kuvvet antremanlarının koordinasyon gelişimi üzerine etkisi. Ankara: Nobel Bilimsel Eserler. [In Turkish]

UNESCO. (2020). Education: From disruption to recovery. Paris. Retrieved from https://en.unesco.org/covid19/ educationresponse

Warren, T.Y., Barry, V., Hooker, S.P., Sui, X., Church, T.S. \& Blair, S.N. (2010). Sedentary behaviors increase risk of cardiovascular disease mortality in men. Med Sci Sports Exerc, 42(5), 879-85.

WHO (2020). Coronavirus Disease (COVID-19) Technical guidance: Guidance for schools, workplaces and institutions. Report. Available online at: https://www.who.int/publications/i/item/consideratio ns-for-school-related-public-health-measures-in-thecontext-of-covid-19 (Accessed August 03, 2020).

Young, D.R., Hivert, M.F., Alhassan, S., Camhi, S.M., Ferguson, J.F \& Katzmarzyk, P.T. (2016). Sedentary behavior and cardiovascular morbidity and mortality: a science advisory from the American Heart Association. Circulation, 134(13), e262-e79. 
Zhou, J., Xie, X., Guo, B., Pei, R., Pei, X., Yang, S. \& Jia, P. (2021). Impact of COVID-19 Lockdown on Physical Activity Among the Chinese Youths: The COVID-19 Impact on
Lifestyle Change Survey (COINLICS). Front Public Health 9, 592795. 